13 Testa D, Savoiardo M, Fetoni V, et al. Multiple system atrophy: clinical and MR observations on 42 cases. Ital $\mathcal{F}$ $14: 211-6$

14 Wenning GK, Jager R, Kendall B, et al. Is cranial computerised tomography useful in the diagnosis of multiple system atrophy? Mov Disord 1994;9:333-6.
15 Quinn N. Multiple system atrophy: the nature of the beast. J Neurol Neurosurg Psychiatry 1989; (special supplement) 52: Neurol

16 Landis JR, Koch GG. The measurement of observer agreement for categorical data. Biometrics 1977;33: $159-74$.

\title{
A giant cauda equina ependymoma
}

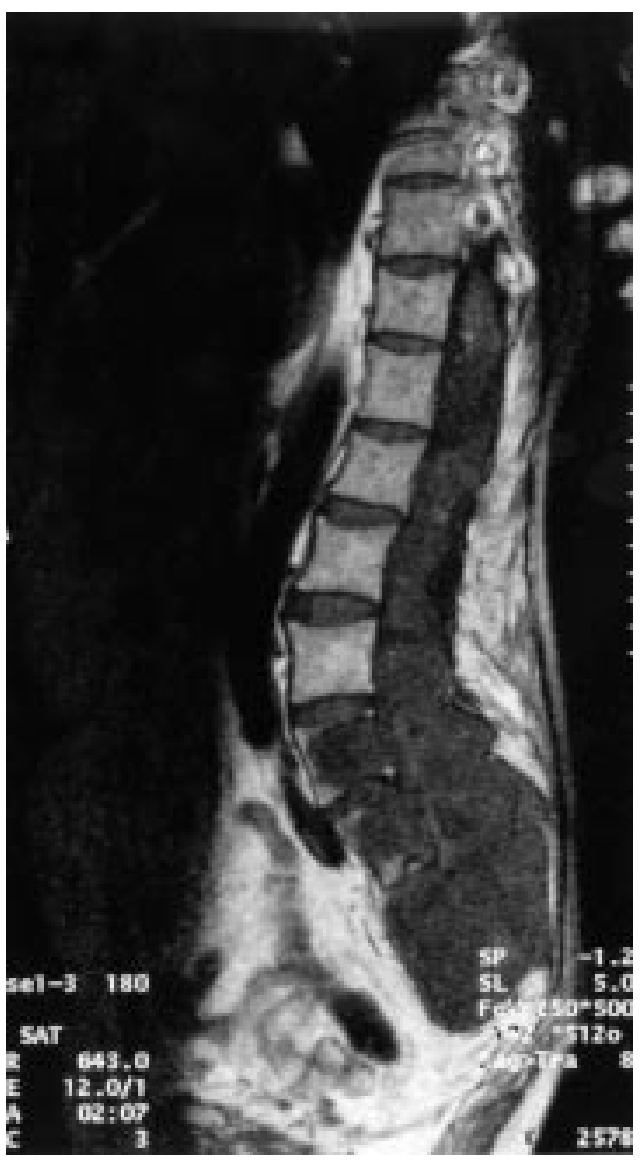

Sagittal T1 (1997) weighted image showing a large tumour arising from the end of the conus filling the whole of the lumbar spine and sacrum.

A 52 year old man presented with slowly progressive signs of a cauda equina lesion. He was incontinent for urine and faeces and could not walk without the aid of a crutch.

In 1960 a sacral biopsy had demonstrated a mixed papillary ependymoma. Despite increasing pain and tumour growth, the patient has always refused surgery.

W H J P LINSSEN Department of Neurology G A G DAVIES Department of Neuroradiology, St Lucas Andreas Hospital, Amsterdam, The Netherlands

Correspondence to: Dr WHJP Linssen, Department of Neurology, St Lucas Andreas Hospital, Jan Tooropstraat 164, PO Box 9243, 1006 AE Amsterdam, The Netherlands. Telephone 0031205108780 ; fax 0031206837198. 